\title{
Adubação nitrogenada e idade de corte na produção de matéria seca do capim-elefante no Cerrado
}

\author{
Rilner A. Flores ${ }^{1}$, Segundo S. U rquiaga $^{2}$, Bruno J. R. Alves ${ }^{2}$, Leonardo S. Collier ${ }^{1}$, \\ Rafael F. de Morais ${ }^{3} \&$ Renato de M. Prado ${ }^{4}$
}

\begin{abstract}
RESU M O
Propôs-se, com este trabalho, avaliar o efeito da aplicação de $\mathrm{N}$ e da idade de corte na produção de biomassa e acúmulo de nitrogênio pelo capim-elefante. 0 experimento foi realizado com o capimelefante cv. Paraíso, cultivado em um Latossolo Vermelho-Amarelo distrófico, município de Gurupi, TO, safra 2008/2009. Foram testadas quatro doses de $\mathrm{N}$-uréia $\left(0,50,100\right.$ e $\left.150 \mathrm{~kg} \mathrm{ha}^{-1}\right)$ e três idades de corte do capim (120, 150 e 180 dias após o brotamento). Avaliou-se, em cada idade de corte, a produção de matéria seca da parte aérea (folhas e colmos) e o acúmulo de $\mathrm{N}$ na planta. A produção de matéria seca do capim-el efante aumentou com a adição de $\mathrm{N}$ porém o efeito foi maior para as plantas cortadas com 180 dias de idade. Encontrou-se um incremento linear na acumulação de matéria seca $\left(R^{2}=0,75^{* *}\right)$ e na acumulação de $\mathrm{N}\left(\mathrm{R}^{2}=0,96^{* *}\right)$, permitindo uma produtividade de $34 \mathrm{t}$ ha-1 de matéria seca, que implicou em uma extração de $\mathrm{N}$ de $471 \mathrm{~kg} \mathrm{ha}^{-1}$. A eficiência de utilização do $\mathrm{N}$ pela cultura variou com o aumento da idade da planta, o que significou maior quantidade de biomassa por unidade de $\mathrm{N}$ absorvido. 0 índice de eficiência mostra que o corte tardio pode favorecer a qualidade da biomassa para fins energéticos, por se tratar de um material mais fibroso.
\end{abstract}

Palavras-chave: Pennisetum purpureum, biomassa, bioenergia

\section{Effect of nitrogen fertilizer and cutting age on the dry matter production of elephant grass in Savana}

\begin{abstract}
The objective of this study was to investigate the effect of the application of $\mathrm{N}$ fertilizer and the cutting age on the dry biomass production of elephant grass. The experiment was performed with the variety Paraíso and planted in a Ferralsol in 2008 in the district of Gurupi (State of Tocantins). Four different rates of urea application were tested $\left(0,50,100\right.$ and $\left.150 \mathrm{~kg} \mathrm{ha}^{-1}\right)$ and harvests were made at 120,150 or 180 days after germination (DAG) of the setts. The dry matter and total $\mathrm{N}$ accumulation were evaluated. D ry matter production increased with dose of $\mathrm{N}$, the greatest effect being observed at $180 \mathrm{DAG}$. There was a linear increase in dry matter $\left(\mathrm{R}^{2}=0.75^{* *}\right)$ and $\mathrm{N}$ accumulation $\left(\mathrm{R}^{2}=0.96^{* *}\right)$ permitting a productivity of $34 \mathrm{t}$ ha-1 of dry matter and an accumulation of $471 \mathrm{~kg} \mathrm{~N} \mathrm{ha}^{-1}$. The $\mathrm{N}$ utilization efficiency (biomass production per unit of applied $\mathrm{N}$ ) increased with plant age. The higher efficiency of $\mathrm{N}$ use favored the quality of biomass production for energy production owing to the higher fibre content.
\end{abstract}

Key words: Pennisetum purpureum, biomass, bioenergy

\footnotetext{
${ }^{1}$ Escola de Agronomia e Engenharia de Alimentos/U FG, Campus Samambaia, C. P. 131, CEP 74001-970, G oiânia, G O . E-mail: rilner1@hotmail.com; leouft@gmail.com

2 Embrapa Agrobiologia, BR 465, Km 7, CEP 23890-000, Seropédica, RJ. E-mail: urquiaga@enpab.embrapa.br; bruno@cnpab.embrapa.br ${ }^{3}$ Instituto Federal de Roraima, Campus Amajari, Vicinal de Acesso à Vila Brasil, Km 3, CEP 69343-000, Amajari, RR. E-mail: rafaelfiusa@yahoo.com.br ${ }^{4}$ U niversidade Estadual Paulista "Júlio de Mesquita Filho", Via de Acesso Prof. Paulo Donato Castellane, s/n, CEP 14870-000, Jaboticabal, SP. E-mail: rmprado@fcav.unesp.br
} 


\section{INTRODUÇÃO}

A produção de material energético alternativo através de biomassa vegetal representa, hoje, um dos grandes desafios para a pesquisa já que, além de ser finita, a continuação da queima desenfreada de petróleo, contribui para o efeito estufa que ameaça o equilíbrio do clima do planeta (Scarlat et al., 2011). Assim, o problema da demanda energética vem-se tornando uma preocupação mundial. Muitos países vêm buscando alternativas ao uso de combustíveis fósseis reduzindo a dependência do petróleo e derivados (Monti et al., 2007). Como a queima de biomassa somente recicla $\mathrm{CO}_{2}$ que foi retirado da atmosfera pela fotossíntese tudo indica que, em longo prazo, esta será uma das alternativas energéticas mais seguras, desde que produzidas eficientemente (Kalt \& Kranzl, 2011).

O uso da biomassa de gramíneas de metabolismo $\mathrm{C} 4$ de alto potencial produtivo como Miscanthus e Panicum vem se destacando na produção de bioenergia (Schemer et al., 2008; Hong et al., 2011) e no Brasil o capim-elefante (Pennisetum purpureum Schum.) vem sendo avaliado para este fim, especialmente pela alta produtividade, qualidade da biomassa e pequena demanda de insumos para produção (Samson et al., 2005; Morais et al., 2011).

O melhoramento genético do capim-elefante e as propostas de manejo para alimentação animal associaram a cultura à necessidade de aplicação de altas doses de fertilizante nitrogenado (Carvalho et al., 1997). O excesso de fertilizantes, especialmente do nitrogenado, eleva o custo energético de produção da biomassa pois a síntese de amônia, por exemplo, requer alto investimento de energia fóssil e assim a produção do fertilizante, processamento e transporte representam não apenas o custo energético mas também emissões de gases de efeito estufa (Robertson \& Grace, 2004).

Uma possibilidade para reduzir o uso da fertilização nitrogenada na cultura pode estar na adequação do regime de cortes da parte aérea que, conhecidamente, permite incrementos significativos na produção de matéria seca de gramíneas (Magalhães et al., 2009). Estudos realizados com diversos genótipos de capim-elefante mostraram a possibilidade de alta produtividade de biomassa com dois cortes ao ano, sem a aplicação de fertilização nitrogenada (Morais et al., 2009). A fixação biológica de $\mathrm{N}_{2}(\mathrm{FBN})$ parece ser responsável por parte significativa do $\mathrm{N}$ requerido pela cultura (Morais et al., 2011) porém, como é um processo que supre parcialmente a necessidade de $\mathrm{N}$ da cultura, a fertilização nitrogenada se torna necessária para manter o balanço de $\mathrm{N}$ do sistema na neutralidade.

A produção anual de biomassa seca do capim-elefante na região Sudeste do Brasil pode superar $50 \mathrm{Mg} \mathrm{ha}^{-1}$, desde que genótipos eficientes sejam usados em função das condições edafoclimáticas favoráveis ao crescimento da cultura (Carvalho et al., 1997; Morais et al., 2009). Para a região dos cerrados o manejo dos cortes é um desafio em função da estiagem que ocorre em 4 a 6 meses do ano.

Para a condição dos cerrados o melhor manejo do capimelefante, especialmente com uso de doses adequadas de nitrogênio associado com idade de corte ótimas, poderá aumentar a eficiência de produção de biomassa apresentando, ainda, melhores possibilidades para o uso do capim-elefante como fonte alternativa de energia.

Diante deste contexto objetivou-se avaliar o efeito da aplicação de nitrogênio e das idades de corte na produção de biomassa e no acúmulo de nitrogênio pelo capim-elefante nas condições dos cerrados.

\section{Material e MÉTOdos}

$\mathrm{O}$ experimento foi realizado na área experimental da Universidade Federal do Tocantins, em Gurupi, TO, num Latossolo Vermelho-Amarelo distrófico (EMBRAPA, 2006). Antes da implantação deste trabalho a área foi cultivada durante oito anos em sistema de plantio direto, com uso de plantas leguminosas, como crotalária, feijão guandu e feijão de porco, usadas como adubo verde da cultura principal.

Para este estudo os tratamentos utilizados foram doses de nitrogênio: 0 (controle), 50,100,150 $\mathrm{kg} \mathrm{ha}^{-1} \mathrm{ano}^{-1}$, na forma de uréia e três idades de corte da parte aérea do capim-elefante (120, 150 e 180 dias após o plantio), com quatro repetições. Desta forma, o delineamento estatístico global correspondeu a parcelas subdivididas, em que as parcelas receberam os tratamentos que correspondem às quatro doses de nitrogênio e as subparcelas aos tratamentos que correspondem às três idades de corte. Cada unidade experimental foi constituída de 4 linhas de capim-elefante com $5 \mathrm{~m}$ de comprimento, espaçadas $1 \mathrm{~m}$, totalizando $20 \mathrm{~m}^{2}$ por parcela.

Antes da demarcação das parcelas realizou-se a amostragem do solo, na profundidade de $0-20 \mathrm{~cm}$, além de posterior análise química, de acordo com o método proposto pela EMBRAPA (1997), apresentando os seguintes resultados: matéria orgânica $-1,79 \%$; nitrogênio total $-0,11 \% ; \mathrm{pH}\left(\mathrm{H}_{2} \mathrm{O}\right)-5,8 ; \mathrm{Al}^{+3}-0,01$ $\mathrm{cmol}_{\mathrm{c}} \mathrm{dm}^{-3} ; \mathrm{Ca}^{+2}+\mathrm{Mg}^{+2}-3,19 \mathrm{cmol}_{\mathrm{c}} \mathrm{dm}^{-3} ; \mathrm{K}^{+}-63 \mathrm{mg} \mathrm{dm}^{-3}$; fósforo trocável (Mehlich 1) - 5,5 $\mathrm{mg} \mathrm{dm}^{-3}$.

Para o plantio foi realizado o preparo de solo através do sistema convencional, com aração e gradagem e, em seguida, fez-se a abertura dos sulcos para a adubação de correção e posteriormente o plantio do capim-elefante.

O genótipo Paraíso foi selecionado por sua rusticidade e alta produção de biomassa, sendo um híbrido de capim-elefante resultado do cruzamento do capim-elefante comum (Pennisetum purpureum Schum.) com o milheto (Pennisetum americanum $\mathrm{L}$.).

O plantio foi realizado em $1^{\circ}$ de dezembro de 2008 , através de sementes; a adubação correspondeu à aplicação de 100 $\mathrm{kg} \mathrm{ha}^{-1}$ de $\mathrm{K}_{2} \mathrm{O}$, na forma de cloreto de potássio, de $100 \mathrm{~kg} \mathrm{ha}^{-1}$ de $\mathrm{P}_{2} \mathrm{O}_{5}$ na forma de superfosfato simples e a adubação nitrogenada na forma de uréia, de acordo com tratamentos, feita no fundo do sulco e sem parcelamento.

Durante o período experimental (outubro de 2008 a maio de 2009) foram efetuadas duas capinas mecânicas, com 30 e 60 dias após o plantio do capim-elefante, período em que foram coletados dados meteorológicos na área, tendo-se registrado temperaturas mínimas de 20,5 a $22,4^{\circ} \mathrm{C}$, e máximas de 30,4 a 31,9 ${ }^{\circ} \mathrm{C}$, e volumes mensais de chuvas entre 155 e $283 \mathrm{~mm}$. Somente no mês de maio de 2009 se registrou um volume baixo de chuvas, 
de $70 \mathrm{~mm}$. Notou-se que, durante o ciclo do capim, não houve restrição térmica ou hídrica importante que pudesse limitar o desenvolvimento da cultura. Os dados de precipitação ocorrida neste período evidenciam que o estudo foi realizado aproveitando-se a maior parte do período chuvoso da região de Gurupi, TO.

Com vista à avaliação da produção de matéria seca do capimelefante, realizou-se a colheita da biomassa aos 120, 150 e 180 dias após o brotamento (DAB). Por ocasião de cada corte foram consideradas as duas linhas centrais de cada parcela, totalizando $10 \mathrm{~m}^{2}$. A biomassa das parcelas foi medida e logo após foram retiradas subamostras de caule e da folha e levadas à estufa de secagem a $65{ }^{\circ} \mathrm{C}$ até atingir massa constante e determinada a matéria seca das plantas. Após a determinação da produção de matéria seca nos colmos e folhas em separado, as amostras foram passadas em moinho tipo Willey (peneiras de $2 \mathrm{~mm}$ ), para determinação do teor de N-total no tecido vegetal, seguindo a metodologia descrita por Alves et al. (1994). Com dados da matéria seca e do teor de $\mathrm{N}$, realizou-se o cálculo do acúmulo de nitrogênio nos colmos, folhas e na parte aérea da planta (colmos + folhas). Também foi realizado o cálculo da eficiência de utilização do nitrogênio (EU) pelo capim-elefante, ou seja, a capacidade da planta em converter o nutriente absorvido em matéria seca total, através da seguinte fórmula: $\mathrm{EU}=(\mathrm{MS} \text { Parte Aérea })^{2} /$ (Acúmulo de Nitrogênio na Parte Aérea) proposto por Prado (2008).

As análises estatísticas foram realizadas com auxílio do software estatístico Sisvar 4.3, realizando-se a análise de variância com a aplicação do teste $\mathrm{F}$ de Fisher e, para as variáveis cujo teste $\mathrm{F}$ foi significativo, comparou-se as médias de tratamentos pelo teste de Tukey e por regressão polinomial.

\section{RESULTADOS E DISCUSSÃO}

A aplicação de doses crescentes de nitrogênio juntamente com a idade de corte do capim-elefante, incrementou significativamente a produção de matéria seca de colmos, de folhas e da parte aérea (Tabela 1). Também foram observadas interações significativas entre as doses de nitrogênio aplicadas e a idade de corte da forrageira para a produção de matéria seca de folhas, colmos e da parte aérea (Tabela 1). Após o estudo da regressão polinomial para o desdobramento das interações, foram observados ajustes quadráticos significativos para o corte do capim realizado aos 120 e 150 dias após o brotamento, atingindo 25,1 e 25,9 $\mathrm{Mg} \mathrm{ha}^{-1}$ de matéria seca de colmos nas doses de 111,8 e 117,8 $\mathrm{kg} \mathrm{ha}^{-1}$ de $\mathrm{N}$, respectivamente (Figura 1A). Para a produção de matéria seca de colmos no corte realizado aos 180 dias observou-se um ajuste linear significativo atingindo 34,1 $\mathrm{Mg} \mathrm{ha}^{-1}$ na dose de $150 \mathrm{~kg} \mathrm{ha}^{-1} \mathrm{de} \mathrm{N}$ (Figura 1A). Em estudos realizados por Silva (2007) com capim-marandu, nos quais foram avaliadas a influência de doses e as fontes de $\mathrm{N}$ em dados de produção, constatou-se um ajuste linear crescente com as doses de $\mathrm{N}$ aplicadas para a produção de colmos.

Em relação à produção de matéria seca de folhas, a aplicação de doses crescentes de nitrogênio apresentou incrementos
Tabela 1. Produção de matéria seca do capim-elefante cv. Paraíso em função da aplicação de nitrogênio e dsa idades de corte, cultivado em Gurupi, TO

\begin{tabular}{|c|c|c|c|}
\hline \multirow{2}{*}{ Tratamentos } & \multicolumn{3}{|c|}{ Matéria seca - Mg ha ${ }^{-1}$} \\
\hline & Folha & Colmo & Parte aérea \\
\hline \multicolumn{4}{|c|}{ Doses (D) (kg ha-1 de N) } \\
\hline 0 & 4,39 & 23,55 & 27,94 \\
\hline 50 & 5,26 & 27,10 & 32,36 \\
\hline 100 & 5,12 & 26,36 & 31,48 \\
\hline 150 & 5,77 & 28,43 & 34,20 \\
\hline Teste $\mathrm{F}$ & $35,84 * *$ & $311,79 * *$ & $454,52 * *$ \\
\hline \multicolumn{4}{|c|}{ Idade (I) (dias após brotamento) } \\
\hline 120 & 4,03 & 24,17 & 28,20 \\
\hline 150 & 5,15 & 24,85 & 30,00 \\
\hline 180 & 6,23 & 30,06 & 36,29 \\
\hline \multirow[t]{2}{*}{ Teste F } & $453,31 * *$ & $707,73^{* *}$ & $940,75^{* *}$ \\
\hline & & Teste $\mathrm{F}$ & \\
\hline (D) $x(I)$ & $17,68^{* *}$ & $48,32 * *$ & $55,24 * *$ \\
\hline C.V. $(\%)$ & 6,40 & 1,90 & 1,80 \\
\hline
\end{tabular}

lineares significativos nas três idades de corte avaliadas (120, 150 e 180 dias após o brotamento), atingindo 4,3; 5,9 e 7,2 Mg $\mathrm{ha}^{-1}$ na maior dose de nitrogênio aplicada, respectivamente (Figura 1B). Os resultados foram semelhantes aos obtidos por Morais et al. (2009), que trabalharam com seleção de genótipos de capim-elefante e obtiveram, após seis meses de cultivo do capim, uma produção de folhas variando entre 4,8 e 7,8 Mg de MS ha-1. Silva (2007) verificou, estudando a eficiência da adubação nitrogenada do capim-marandu de pastagens tratadas com doses e fontes de nitrogênio, um ajuste quadrático para a produção de biomassa de folhas usando a uréia como fonte fornecedora de $\mathrm{N}$ ao solo atribuindo, à queda na resposta da adubação nitrogenada, o fato de existirem grandes transformações da uréia no solo que levaram a perdas por volatilização de amônia.

Em condições elevadas de temperatura, ausência imediata de precipitação logo após a aplicação do adubo e altas taxas de evapotranspiração de água do solo, as perdas por volatilização podem atingir cerca de $60 \%$ do $\mathrm{N}$ na forma de uréia comprometendo a produtividade da planta forrageira (Araújo et al., 2009).

Ao contrário do observado neste estudo, Queiroz Filho et al. (2000) constataram resposta linear negativa para a produção de folhas de capim-elefante genótipo Roxo em função do aumento do intervalo de corte, uma vez que esta avaliação foi realizada até completar 100 dias após o plantio. Leite et al. (2000) também notaram resposta linear negativa para a produção de folhas em função do aumento do intervalo de corte em capimelefante genótipo Cameroon.

No presente estudo a idade de corte mais antecipada ocorreu aos 120 DAB e a mais tardia, aos 180 DAB. O aumento na produção de biomassa seca de folhas pode ter sido influenciado pelas condições climáticas ocorridas durante a condução do experimento, com precipitações bem distribuídas e temperatura elevada até o fim do período de estudo, favorecendo a emissão de novas folhas incrementando, por sua vez, a produção de 
A.

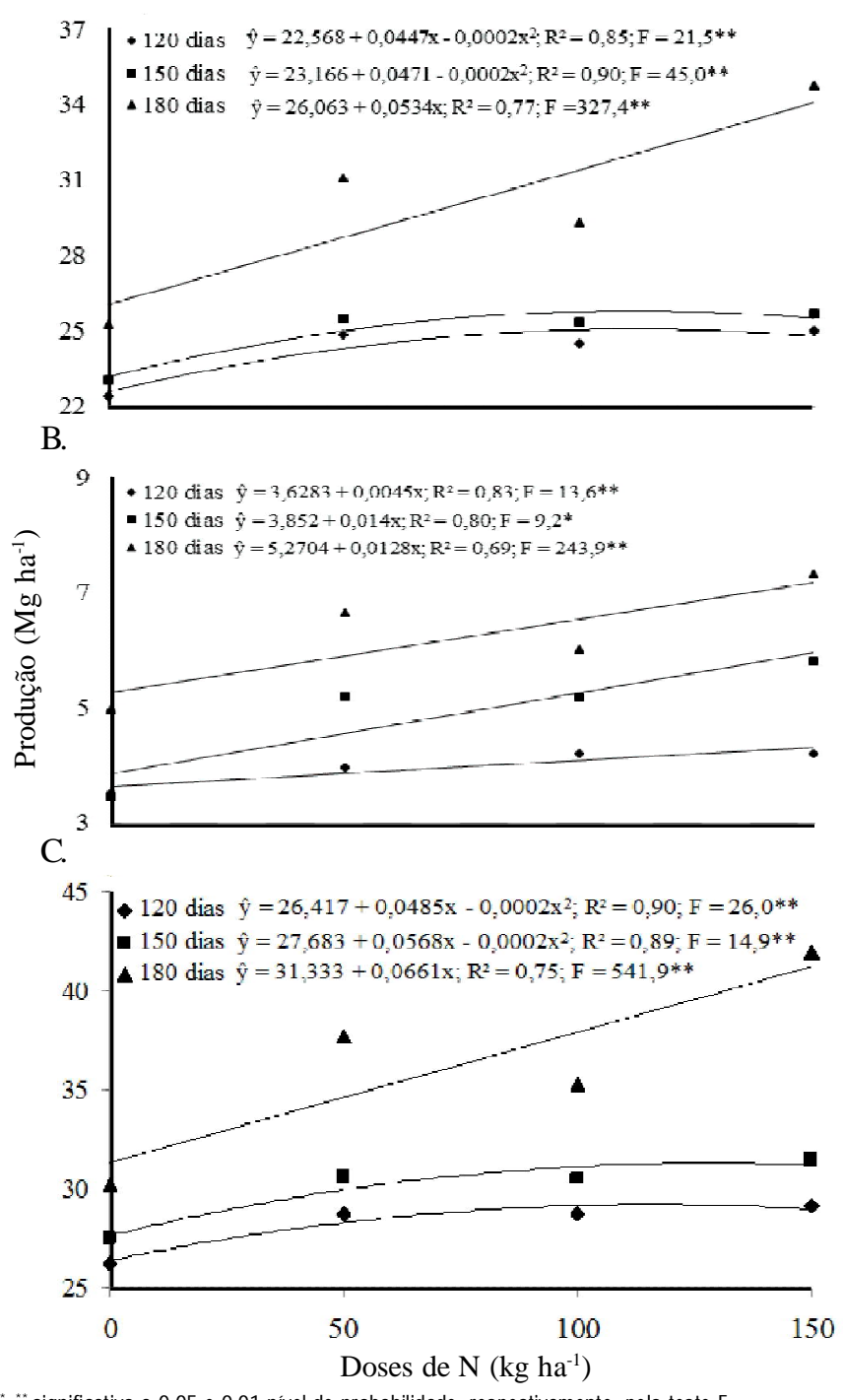

"** significativo a 0,05 e 0,01 nível de probabilidade, respectivamente, pelo teste $\mathrm{F}$

Figura 1. Produção de matéria seca de folha (A); colmo (B) e da parte aérea (C) do capim-el efante cv. Paraíso, em função da aplicação de nitrogênio e das idades de corte, cultivado em G urupi, TO

matéria seca com o aumento do intervalo de corte do capimelefante. Outros estudos nos quais se avaliou a idade de corte de capim-elefante sobre o rendimento desta forragem, também registraram incrementos da produção de matéria seca com aumento dos intervalos de corte (Queiroz Filho et al., 2000; Leite et al., 2000; Magalhães et al., 2006).

A produção total de matéria seca de capim-elefante também apresentou uma interação entre a dose de $\mathrm{N}$-fertilizante aplicado com a idade de corte porém essas interações nos cortes realizados aos 120 e 150 dias após o brotamento foram com ajustes quadráticos, atingindo 29,4 e $31,7 \mathrm{t} \mathrm{ha}^{-1}$ nas doses de $121,2 \mathrm{e} 142 \mathrm{~kg} \mathrm{ha}^{-1} \mathrm{de} \mathrm{N}$ (Figura 1C).

No corte realizado aos 180 dias após o brotamento observouse um ajuste significativo linear, atingindo $41,2 \mathrm{t} \mathrm{ha}^{-1}$ na maior dose aplicada de $\mathrm{N}$-fertilizante (Figura 1C).

Saraiva \& Carvalho (1991) não observaram efeito de doses de $\mathrm{N}$ até $120 \mathrm{~kg} \mathrm{ha}^{-1}$, combinadas com níveis de adubação fosfatada sobre a produção de matéria seca do capim-elefante cv. Mineiro. Por outro lado, Rocha et al. (2002) observaram, avaliando o efeito do nitrogênio em capim do gênero Cynodon, resposta até a dose de $400 \mathrm{~kg} \mathrm{ha}^{-1} \mathrm{de} \mathrm{N}$. Em vários trabalhos realizados para avaliar a resposta à adubação nitrogenada em capim-elefante, houve aumento na produção de matéria seca em função do aumento da dose de nitrogênio aplicado (Andrade et al., 2003; Magalhães et al., 2006; Pegoraro et al., 2009; Vitor et al., 2009).

Com o favorecimento das condições edafoclimáticas da região, ou seja, aumento das chuvas e temperatura durante o período de condução do experimento e com uma temperatura média de $25{ }^{\circ} \mathrm{C}$, o capim-elefante pode desenvolver-se com maior facilidade atingindo, no final dos 90 dias após o plantio, uma altura de aproximadamente $2 \mathrm{~m}$ e com maior aporte de biomassa haja vista que essas condições, segundo Silva et al. (2010) estão próximas às ideais para a produção de capimelefante.

Em relação à influência da dose de $\mathrm{N}$ aplicada no cálculo da eficiência de nutricional, notou-se que a dose de $50 \mathrm{~kg} \mathrm{ha}^{-1} \mathrm{e} \mathrm{o}$ corte realizado aos 180 dias após o brotamento foram os que proporcionaram a maior eficiência de utilização (Tabela 2) possibilitando a maior economia de $\mathrm{N}$-fertilizante no sistema de produção para obter maiores ganhos de produtividade com menor demanda de energia fóssil provindo dos fertilizantes nitrogenados.

Tabela 2. Acúmulo de nitrogênio nas folhas, colmo e parte aérea do capim-elefante cv. Paraíso, em função da aplicação de nitrogênio e das idades de corte, cultivado em Gurupi, TO

\begin{tabular}{|c|c|c|c|c|}
\hline \multirow{3}{*}{ Tratamentos } & \multicolumn{3}{|c|}{ Acúmulo de nitrogênio } & \multirow{3}{*}{$\begin{array}{l}\text { Eficiência } \\
\text { de utilização }\end{array}$} \\
\hline & Folha & Colmo & Parte aérea & \\
\hline & \multicolumn{3}{|c|}{$\mathrm{kg} \mathrm{ha}^{-1}$} & \\
\hline \multicolumn{5}{|l|}{ Doses (D) } \\
\hline 0 & 68,53 & 287,73 & 356,26 & 2191,2 \\
\hline 50 & 76,46 & 318,58 & 395,04 & 2650,8 \\
\hline 100 & 80,99 & 341,19 & 422,18 & 2347,3 \\
\hline 150 & 90,37 & 381,05 & 471,42 & 2481,1 \\
\hline Teste F & $6,51^{*}$ & $67,91 * *$ & $390,18^{* *}$ & - \\
\hline \multicolumn{5}{|l|}{ Idade (I) } \\
\hline 120 & 61,81 & 305,92 & 367,73 & 2162,6 \\
\hline 150 & 74,92 & 322,61 & 397,53 & 2264,0 \\
\hline 180 & 100,54 & 367,89 & 468,43 & 2811,4 \\
\hline Teste F & $69,08^{* *}$ & $60,14 * *$ & $1569,41 * *$ & - \\
\hline \multicolumn{5}{|c|}{ Teste F } \\
\hline (D) $\times(I)$ & $3,18^{*}$ & $9,39 * *$ & $104,41^{* *}$ & - \\
\hline C.V. $(\%)$ & 15,60 & 5,00 & 2,00 & - \\
\hline
\end{tabular}

A adubação nitrogenada, idades de cortes e também suas interações, influenciaram o acúmulo de nitrogênio nas folhas do capim-elefante (Tabela 2). Notou-se que a interação entre as doses de nitrogênio e a idade de corte do capim-elefante para o acúmulo de nitrogênio ocorreu nas folhas, no colmo e na parte aérea (Tabela 2). Esses resultados corroboram o que foi encontrado por Fagundes et al. (2007) que, avaliando a influência da adubação nitrogenada para a produção de 
biomassa seca de capim-elefante cv. Guaçu, observaram aumento da extração de $\mathrm{N}$ por esta cultura em função do aumento das doses de nitrogênio aplicadas atingindo, na dose de 240 $\mathrm{kg} \mathrm{ha}^{-1}$ uma extração equivalente acima de $300 \mathrm{~kg} \mathrm{ha}^{-1} \mathrm{de} \mathrm{N}$ com uma produção de biomassa seca cerca de $30 \mathrm{Mg} \mathrm{ha}^{-1}$.

Após o estudo da regressão polinomial para o desdobramento das interações foram observados ajustes lineares significativos no acúmulo de $\mathrm{N}$ no colmo nas três idades de corte avaliadas, atingindo 334,$4 ; 351,2$ e $441,9 \mathrm{~kg}$ de $\mathrm{N} \mathrm{ha}^{-1}$ na maior dose de $\mathrm{N}$ fertilizante aplicada no corte realizado aos $120 ; 150$ e 180 dias após o brotamento, respectivamente (Figura $2 \mathrm{~B}$ ). Esses valores encontrados são altos quando comparados aos obtidos por Morais et al. (2009) que encontraram um acúmulo de N no colmo

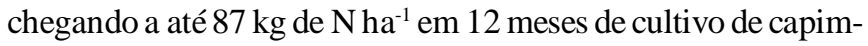
elefante, uma vez que o presente estudo avaliou o acúmulo do nitrogênio no colmo até $180 \mathrm{DAB}$, ou seja, a metade do tempo gasto no estudo realizado por Morais et al. (2009).

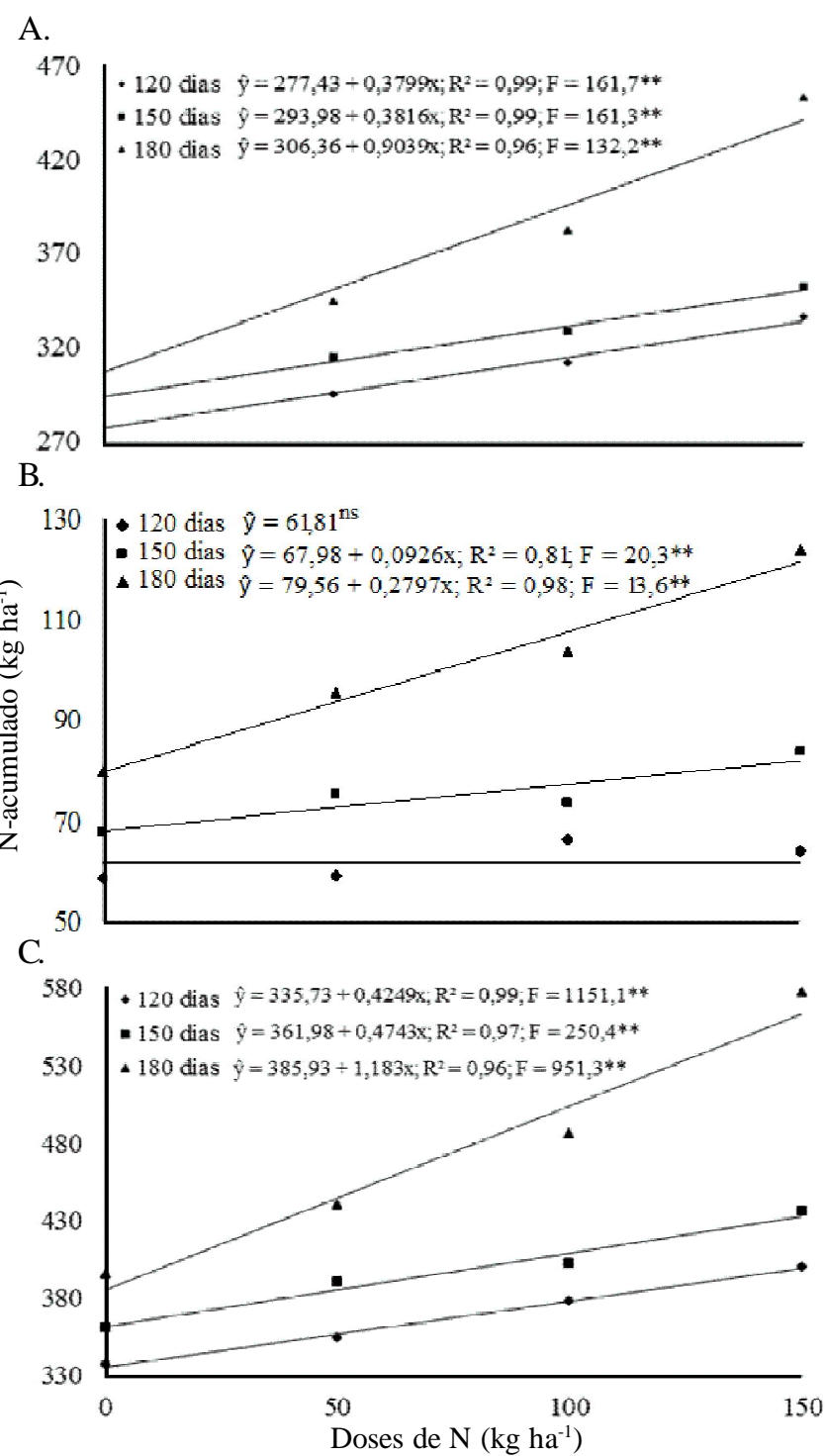

ns, "** não significativo a 0,05, e significativo a 0,01 nível de probabilidade, respectivamente, pelo teste $F$

Figura 2. Nitrogênio acumulado na folha (A), no colmo (B) e na parte aérea $(C)$ do capim-elefante Cv. Paraíso em função aplicação de nitrogênio e das idades de corte, cultivado em G urupi, TO
Obtiveram, quando se avaliou o teor de $\mathrm{N}$ acumulado nas folhas, ajustes lineares significativos apenas para os cortes realizados aos 150 e $180 \mathrm{DAB}$, atingindo 81,9 e $121,5 \mathrm{~kg}$ de N ha $^{-1}$ na maior dose de $\mathrm{N}$-fertilizante aplicada, respectivamente (Figura 2). A aplicação de doses crescentes de $\mathrm{N}$-fertilizante não afetou o acúmulo de $\mathrm{N}$ nas folhas do capim-elefante no corte realizado aos 120 dias após o brotamento mas apresentou

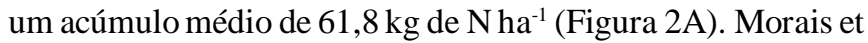
al. (2009) verificaram acúmulos de nitrogênio na folha de capimelefante na ordem de $136 \mathrm{~kg} \mathrm{ha}^{-1}$ de $\mathrm{N}$ em estudo realizado com 12 meses de cultivo de capim-elefante. São esperados maiores acúmulos de nutrientes com o maior intervalo de corte do capimelefante uma vez que, com maior tempo decorrido, houve aumento da produção de biomassa.

Da mesma forma que nos colmos, foram observados ajustes lineares significativos para o acúmulo de $\mathrm{N}$ na parte aérea do capim-elefante nas três idades de corte avaliadas, atingindo 399,$5 ; 433,1$ e $563,4 \mathrm{~kg}$ de $\mathrm{N} \mathrm{ha}^{-1}$ na maior dose de $\mathrm{N}$-fertilizante aplicada no corte realizado aos $120 ; 150$ e 180 DAB, respectivamente (Figura 2C).

Mesmo na ausência da aplicação de N-fertilizante houve alto acúmulo de $\mathrm{N}$, sendo explicado pelo alto teor deste nutriente no solo, durante a condução do experimento e, possivelmente, pela contribuição da fixação biológica de $\mathrm{N}_{2}(\mathrm{FBN})$ visto que Morais et al. (2011) observaram contribuições da FBN acima de 50\% da exigência em N em capim-elefante. Quesada (2005) encontrou acúmulo de $\mathrm{N}$ próximo $270 \mathrm{~kg}$ de $\mathrm{N} \mathrm{ha}^{-1}$ com corte da planta aos 15 meses de cultivo de capim-elefante cultivado em um Planossolo com teor de $\mathrm{N}$ total no solo de $0,48 \mathrm{~g} \mathrm{dm}^{-3}$, e

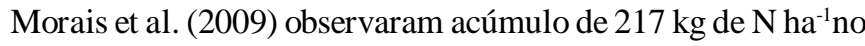
capim-elefante cultivar Cameroon com corte realizado aos 12 meses após o plantio, cultivado em um Argissolo VermelhoAmarelo, textura média com teor de $\mathrm{N}$ total no solo de $1,1 \mathrm{~g} \mathrm{dm}^{-}$ ${ }^{3}$. O solo deve ter contribuído, sem dúvida, em todos esses estudos, com grande parte do $\mathrm{N}$ utilizado pela cultura, tornando essencial a reposição através de fertilizantes ou adubos verdes, por exemplo.

O capim-elefante é uma planta exigente em nutrientes, em decorrência do seu elevado potencial de produção, sendo a extração de nutrientes do solo pela forrageira, proporcional aos rendimentos de biomassa. Com o manejo e a adubação intensivos verifica-se, normalmente, uma remoção significativa desses nutrientes, em especial do nitrogênio (Morais et al., 2011).

Embora o estudo tenha sido feito em um solo de fertilidade média, as altas produções de biomassa de capim-elefante associadas aos altos níveis de $\mathrm{N}$ acumulado na planta podem ser atribuídas, pelo menos em parte, à alta disponibilidade de $\mathrm{N}$ do solo após vários anos de cultivo com leguminosas com alta eficiência de FBN como crotalária, feijão de porco e feijão caupi, antes do início deste experimento.

É oportuno destacar que a produção obtida de capimelefante e seu desempenho na utilização do $\mathrm{N}$ do fertilizante, foram derivados de apenas um corte com 4 a 6 meses, havendo a possibilidade de ampliação dessa produção e a utilização de $\mathrm{N}$, após rebrota e crescimento do capim durante o restante do ano. 


\section{CONCLUSÃO}

Nas condições de cerrado e durante a estação das chuvas, a produtividade responde diretamente ao tempo de permanência para o primeiro corte, sendo significativamente ampliada com o aumento das doses de $\mathrm{N}$.

\section{LITERATURA CITADA}

Alves, B. J. R.; Santos, J. C. F.; Urquiaga, S.; Boddey, R. M. Métodos de determinação do nitrogênio em solo e planta. In: Hungria, M.; Araújo, R. S. (ed.). Manual de métodos empregados em estudos de microbiologia agrícola. Brasília: Embrapa SPI, 1994. p.409-449.

Andrade, A. C.; Fonseca, D. M.; Queiroz, D. S.; Salgado, L. T.; Cecon, P. R. Adubação nitrogenada e potássica em capimelefante (Pennisetum purpureum Schum. cv. Napier). Revista Ciência Agrotécnica, Edição especial, p.1643-1651, 2003.

Araújo, E. S.; Marsola, T.; Miyazawa, M.; Soares, L. H. B.; Urquiaga, S.; Boddey, R. M.; Alves, B. J. R. Calibração de câmara semiaberta estática para quantificação de amônia volatilizada do solo. Pesquisa Agropecuária Brasileira, v.44, p.769-776, 2009.

Carvalho, M. M.; Alvin, M. J.; Xavier, D. F.; Carvalho, L. M. Capim-elefante: produção e utilização. 2.ed. Coronel Pacheco: Embrapa Gado de Leite, 1997. 219p.

EMBRAPA - Empresa Brasileira de Pesquisa Agropecuária. Manual de métodos de análise de solos. 2.ed. Rio de Janeiro: Embrapa CNPS 1997. 212p. Documento 1

EMBRAPA - Empresa Brasileira de Pesquisa Agropecuária. Sistema brasileiro de classificação de solos, Rio de Janeiro: EMBRAPA, 2006. 412p.

Fagundes, J. L.; Fonseca, D. M.; Mistura, C.; Salgado, L. T.; Queiroz, D. S.; Morais, R. V.; Vitor, C. M. T.; Moreira, L. M. Adubação nitrogenada e potássica em capim elefante cv. Napier sob pastejo rotativo. Boletim da Indústria Animal, v.64, p.149-158, 2007.

Hong, C.; Fang, J.; Aiwu, J.; Cai, J.; Guo, H.; Ren, J.; Shao, Q.; Zheng, B. Comparative Growth, Biomass Production and Fuel Properties Among Different Perennial Plants, Bamboo and Miscanthus. The Botanical Review, v.77, p.197-207, 2011.

Kalt G.; Kranzl, L. Assessing the economic efficiency of bioenergy technologies in climate mitigation and fossil fuel replacement in Austria using a techno-economic approach, Applied Energy, v.88, p.3665-3684, 2011.

Leite, R. M. B.; Queiroz Filho, J. L. de; Silva, D. S. Produção e valor nutritivo do capim-elefante cultivar Cameroon em diferentes idades. Agropecuária Técnica, v.21, p.30-39, 2000.

Magalhães, J. A.; Lopes, E. A.; Rodrigues, B. H. N.; Costa, N. L.; Barros, N. N.; Mattei, D. A. Influência da adubação nitrogenada e da idade de corte sobre o rendimento forrageiro do capim-elefante, Revista Ciência Agronômica, v.37, p.91-96, 2006.
Magalhães, J. A.; Rodrigues, B. H. N.; Carneiro, M. S. S.; Andrade, A. C.; Pinto, M. S. C.; Ericeira, W. J. Influencia da adubação nitrogenada e idade de corte sobre os teores de proteína bruta e fibra em detergente neutro de três cultivares de capim-elefante. Revista Electrónica de Veterinária, v.10, p.1695-1702, 2009.

Monti, A.; Fazio, S.; Lychnaras, V.; Soldatos, P.; Venturi, G. A full economic analysis of switchgrass under different scenarios in Italy estimated by BEE model. Biomass and Bioenergy, v.31, p.177-185. 2007.

Morais, R. F.; Quesada, D. M.; Reis, V. M.; Urquiaga, S.; Alves, B. J. R.; Boddey, R. M. Contribution of biological nitrogen fixation to Elephant grass (Pennisetum purpureum Schum.) Plant and Soil, v.349, p.1-12, 2011.

Morais, R. F.; Souza, B. J.; Leite, J. M.; Soares, L. H.; Alves, B. J.; Boddey, R. M.; Urquiaga, S. Produção, qualidade de biomassa e fixação biológica de $\mathrm{N}$ em genótipos de capimelefante destinados à geração de energia. Pesquisa Agropecuária Brasileira, v.44, p.133-140, 2009.

Pegoraro, R. F.; Mistura, C.; Wendling, B.; Fonseca, D. M. da; Fagundes, J. L. Manejo da água e do nitrogênio em cultivo de capim-elefante. Revista CiênciaAgrotécnica, v.33, p.461-467, 2009.

Prado, R. M. Nutrição de plantas. São Paulo: UNESP, 2008. 407p.

Queiroz Filho, J. L. de; Silva, D. V. da; Nascimento, I. S. Produção de matéria seca e qualidade do capim-elefante (Pennisetum purpureum Schum.) cultivar Roxo em diferentes idades de corte. Revista Brasileira de Zootecnia, v.29, p.69-74, 2000.

Quesada, D. M. Parâmetros quantitativos e qualitativos da biomassa de diferentes genótipos capim-elefante para produção de agroenergéticos. Seropédica: UFRRJ, 2005. 65p. Tese Doutorado

Robertson, G. P.; Grace, P. R. Greenhouse gas fluxes in tropical and temperate agriculture: the need for a full-cost accounting of global warming potentials. Environment, Development and Sustainability, v.6, p.51-63, 2004.

Rocha, G. P.; Evangelista, A. R.; Lima, J. A. de; Rosa, B. Adubação nitrogenada em gramíneas do gênero Cynodon. Ciência Animal Brasileira, v.3, p.1-9, 2002.

Samson, R.; Mani, S.; Boddey, R.; Sokhansanj, S.; Quesada, D.; Urquiaga, S.; Reis, V.; Ho Lem, C. The potential of c4 perennial grasses for developing a global. Bioheat Industry, Plant Science, v.24, p.1-35, 2005.

Saraiva, O. F.; Carvalho, M. M. Adubação nitrogenada e fosfatada para o estabelecimento de capim-elefante em Latossolo Vermelho-Amarelo, textura argilosa. Revista Brasileira de Ciência do Solo, v.15, p.201-205, 1991.

Scarlat, N.; Dallemanda, J.; Skjelhaugenb, O. J.; Asplunde, D.; Nesheim, L. An overview of the biomass resource potential of Norway for bioenergy use. Renewable and Sustainable Energy Reviews, v.15, p.3388-3398, 2011.

Schemer, M. R.; Vogel, K. P.; Mitchell, R. B.; Perrin, R. K. Net energy of cellulosic ethanol from switch grass. Proceedings of the National Academy of Sciences. v.105, p.464-469, 2008.

Silva, A. L. C.; Santos, M. V. F.; Dubeux Júnior, J. C. B.; Lira, M. A.; Ferreira, L. R. C.; Freitas, E. V.; Cunha, M. V.; Silva, M. C. Variabilidade e herdabilidade de caracteres morfológicos em clones de capim-elefante na Zona da Mata de Pernambuco. Revista Brasileira de Zootecnia, v.39, p.2132-2140, 2010. 
Silva, D. R. G. Características estruturais e eficiência da adubação nitrogenada do capim-marandu de pastagens em estágio moderado de degradação sob doses e fontes de nitrogênio. Lavras: UFLA, 2007. 58p. Dissertação Mestrado
Vitor, C. M. T.; Fonseca, D. M.; Cóser, A. C.; Martins, C. E.; Júnior, D. do N. Produção de material seca e valor nutritivo de pastagem de capim-elefante sob irrigação e adubação nitrogenada. Revista Brasileira deZootecnia, v.38, p.435-442, 2009. 